\title{
An analysis of urban system with emphasis on entropy model (Case study: the cities of East Azerbaijan Province)
}

\author{
Hossain Nazmfar \\ Department of Geography and Urban Planning, University of Mohaghegh, Ardabili, Ardabil, Iran, \\ nazmfar1@yahoo.com
}

\begin{abstract}
Nowadays, strong concentration of population and comprehensive facilities and resources in the capital cities and some other metropolises has encountered the countries with many problems, some of which represent many third world countries' problems. For this reason the concept of urban system can be investigated from various aspects. This article aims to include an analysis of urban systems among cities of East Azerbaijan during the time period of 50 years (1957-2007). Some of the problems are the manner of population distribution in the cities, quality of interactions and connection of these areas in urban network, organizing and equilibrating the urban space. Due to the urbanization of this region and high density of Tabriz population and facilities compared with other cities, East Azerbaijan province also faces different challenges. Using quantitative-analytical method, common techniques and models, the research results indicated that population establishment in urban regions is not distributed equally or in a balanced form. The reasons for such findings can be the rise of small and insignificant towns in the urban network of the province and the intense population concentration in Tabriz.
\end{abstract}

Keywords: Urban primacy, entropy, spatial equilibrium, urban system.

\section{Introduction}

Nowadays the main struggle in third world countries is between downtown areas and suburbs. Despite the fact that suburbs have the most inexpensive sources for development, central and developed areas have more abilities for demanding their needs and abilities to attract facilities and control the suburbs (Gilbert, 1989). In Iran, in the past half century, capitalism expansion within oildependent economy has caused stagnation in agriculture and rapid urban growth as well. This rapid growth was not formed in a balanced way and led to the growth of large cities and prevented the growth of small towns and rural areas. The result of this process was unbalancing spatial distribution and area's hierarchy. This rupture and imbalance in urban hierarchy led to the genesis of unfavorable effects on the spatial distribution of the regional and national planning (Nazarian, 2005, 15). So, the country's urban population increased as a result of exogenous developments. The development was fundamentally exogenous, city-oriented and central. This feature increased the number of towns and caused the appearance of bigger cities. Population concentration in large cities is considered as the most important feature of urban system of that period. Centralization caused disorders in the urban network of the country. Therefore major changes occurred in the urban system of the country and led to the changes of cities' galactic network (especially from 1957 onwards) into the linear and chain network in most regions instead of the phenomenon of urban primacy in country - law of size-rank- in province centers (Papoli, 1994). This exogenous development created huge changes in the structure of the country. For instance, from 1921 onwards, the movement towards multilateral (political, administrative, and economic) centralization was accelerated and became institutionalized.

Popular article

CCIndian Society for Education and Environment (iSee)
As a system dependent on the global capitalism, trying to provide the interests of it, the government considered the establishment of security and market creation for joining global markets as its main politicaleconomic goal (Ebrahimzadeh \& Negahban, 2006). Based on this fact, it is necessary to investigate the urban system and the performance of the cities in the regions revealing the current status clearly, to give some solutions for the activists in urban management and planning, by utilizing strengths and weakness points of the current situation. The importance of this issue in East Azerbaijan is because of its urbanization and high population and facilities density compared with other small cities in the area to establish a balance and equitable distribution of facilities as well as reducing population movements. The main aim of this research is analyzing the degree of spatial equilibrium of urban system of East Azerbaijan Province using urban primacy indicator, the model of size-rank, coefficient of entropy, anarchy index and the class difference method within 6 statistical periods (1957-2007).

\section{Methodology}

Exerted methods of this research are of quantitativeanalytical type, representing applied models. In this study, the statistical data of 6 capitation periods have been used (1957-2007). Statistical population of this study included all the cities of the province, declared formally as a city in the capitation. The following models have been used to achieve research objectives: a) Urban primacy index, b) Size-rank model, c) Entropy index, d) Class difference method

Analysis of urban primacy of east Azerbaijan province

The relation of size-rank of East Azerbaijan province shows the imbalance of the urban population hierarchy which is mainly due to the spared of Tabriz, playing multifunctional role in national and international scales. 
Population centralization and activities in Tabriz and increasing the spatial scale of the city have affected all socio-economic activities of urban area by the spatial density of regional functions. The role of urban primacy led to deterioration of activities and inter-regional functions, increasing rural migrations. Urban primacy index was proposed by Mark Jefferson, an American geographer, for the first time in his book named "urban primacy law "in 1939. He determined urban primacy index, using partial method and population data of 44 countries to measure the mentioned procedures. His method measures the ratio of the first city to the second.

\section{$\frac{\mathrm{P}_{1}}{\mathrm{P}_{2}}$}

In 1964, as suggested by Mahta, the best method for determining the urban primacy index is the ratio of the first city to the first four-cities of the urban system.

$$
\frac{\mathrm{P}_{1}}{\sum_{\mathrm{i}=1}^{4} \mathrm{P}_{\mathrm{i}}}
$$

Combining urban primacy index with size-rank model of city population provides a proper criterion for measurement as follows:

$[1 /(1+0.5+0.33+0.25)]=0.48$

This distribution will be the best and common form of urban primacy.

High growth of Tabriz in recent decades was out of sizerank law and gave an undesirable superiority to this city. This index for East Azerbaijan was 0.79\% in 2007.

$$
\frac{\mathrm{P}_{1}}{\sum_{\mathrm{i}=1}^{4} \mathrm{P}_{\mathrm{i}}}
$$

$1398060 /(1398060+149929+114841+89796)=0.79$

In fact, the value of this index shows the urban system pattern and the urban settlements of the province. Considering this index, the population of Tabriz City is 0.79 , among the first four cities of province. This number is regarded in ultra superiority interval of Richardson's urban primacy pattern which shows undesirable distribution. Table 1 shows the superiority degree of first

Table1. Primacy index classification

\begin{tabular}{|l|c|}
\hline \multicolumn{1}{|c|}{ Kind of superiority } & Index of four-cities \\
\hline Ultra superiority & 0.65 to 1 \\
\hline Superiority & 0.54 to 0.65 \\
\hline Desired superiority & 0.41 to 0.54 \\
\hline Minimum superiority & Less than 0.41 \\
\hline
\end{tabular}

city to first four cities.

(Adopted from Azimi, 2003)

According to Table 1, in 2007, the pattern of urban (0.65 to 1$)$. While considering the Maragheh as the first system in East Azerbaijan tends to ultra-superiority index

city of province, urban primacy pattern is in the minimum superiority (0.34). Therefore, it is observed that the urban system hierarchy will be more adaptive with the size-rank law without considering Tabriz population. In this situation, urban primacy index of Jefferson will have minimum superiority in the urban system.

The model of urban size-rank in cities of East Azerbaijan province (1997-2007)

Between captions of 1997 and 2007 some changes have occurred in the population hierarchy of urban settlements of province. Thus in middle hierarchy the population of Sardrood has reached to the rank of 11 from 13. Shabestar population has increased considerably and exceeded the population of Ilkhechi, Mamaghan and Gogan towns. The rank of Shabestar has reached the rank of 17 in 2007 from 20 in 1997. Ilkhechi population has exceeded populations of Mamaghan and Gogan and reached to the rank of 18 in 2007 from 19 in 1997. With 3 step development, Basmenj Town has achieved the rank of 21 in 2007. Kalayber Town has reached the rank of 23 in 2007 from the rank of 27 in 1997. With one step development, Torkamanchay Town has been ranked 29th in 2007 from 30th in 1997; and leylan Town has come to the rank of 32 from 34 .

Also, some changes are observed in the lower ranks of population hierarchy of urban settlements which indicate the changes in the ranking system of the urban population in 2007. In this hierarchy, the cities have been ranked as follows:

With two steps decrease, Mamaghan reached the rank of 19 from 17, with two steps decrease, Gogan reached the rank of from the rank of 20 from 18 . Shendabad reached from 22 to 26, Tasouj reached from 28 to 26, Zarnagh reached from 33 to 37, Vaygan reached from 36 to 41 , Khajeh reached from 37 to 44 , Sharafkhaneh reached from 38 to 43 , Zonouz reached from 39 to 48 , and Khameneh reached from 41 to 48 . Considering available data, more polarization of spatial urban development and continuous macro growth of Tabriz were noticed. Based on the population data in 2007, a part of population in Tabriz City had migrated to the towns near due to land speculation and increases in house prices, traffic problems and other socio-economic problems. Also, in lower ranks, rural-urban migrations and natural increase of population can increase the rank of these cities in population hierarchy.

In east Azerbaijan province the population increased to 1 million a year in East Azerbaijan province, the population increment was 400 thousand people from 1967-1977, 700 thousands from 1977-1987, 280 thousands from 1987-1997 and 278 thousand from 19972007.

Maybe these rapid changes in population and rapid growth of urbanization imply the residency of population in cities and are not necessarily related to the development of urbanization process. In other words, the lack of real social development and promotion of 
Indian Journal of Science and Technology

mechanization in rural areas are the main reasons of rural migration to the cities. Therefore, it seems that the main part of population changes in province and country's cities is related to the inefficiency of the rural systems and the lack of enough production and income in rural areas. It is important to note that marginalization and poverty are other social reasons of migration procedure.

Entropy model (Anarchy index)

Entropy is one of the theories, derived from probability laws and based on probability models. This model initially is applied by the physicians to recognize the regularity and anarchy in nature and it determines the instability and the lack of uniformity in a system. If the entropy tends to zero, it shows more centralization or less balance in population distribution of cities, while the value near 1 indicates more balanced distribution in the region (Hekmatnia \& Moosavi, 2007).

Table 2. Entropy coefficient in 6 statistic periods

\begin{tabular}{|c|c|c|}
\hline Year & Number of cities & Entropy Coefficient \\
\hline 1957 & 19 & 0.562 \\
\hline 1967 & 30 & 0.561 \\
\hline 1977 & 30 & 0.544 \\
\hline 1987 & 30 & 0.524 \\
\hline 1997 & 39 & 0.518 \\
\hline 2007 & 85 & 0.502 \\
\hline
\end{tabular}

Reference: Web-sites of Iran's Statistical Offices and authors' calculations

Basis of this theory is predicting the probability which can help foreseeing future organizational bias of understudy phenomena according to their regular or irregular behaviors in the past. By this model, it is possible to know the spatial balance extent of population and the number of cities in urban, regional and national levels (Wheeler \& Muller, 1986). The more regularity in the past changes of phenomena, the easier it will be to predict an acceptable future form for them. Also, this theory and its techniques are used for describing the settlements, distribution of population in geographic spaces, and the centralization degree of population in a region. The formula of this model is as follows:

$$
\begin{aligned}
& H=\sum_{i=1}^{n} P_{i} \log \frac{1}{P_{i}}=\sum-P_{i} \log P_{i} \\
& R=1-\frac{H}{H_{\max }}=\frac{H}{\log K}
\end{aligned}
$$

Where:

$\mathrm{H}$ : absolute entropy

$\mathrm{P}_{\mathrm{i}}$ : frequency of population class

Log: natural logarithm

$\mathrm{R}$ : relative entropy

$\mathrm{H}_{\text {max }}$ : maximum absolute entropy which equals uniform distribution of population

To calculate the entropy, it should be used from obtained ratios of population calculations in each sub areas $\left(P_{i}\right)$.
Vol. 5 No. 9 (Sep. 2012) ISSN: 0974- 6846

Fig. 1. Entropy Coefficient of urban system of East Azerbaijan Province

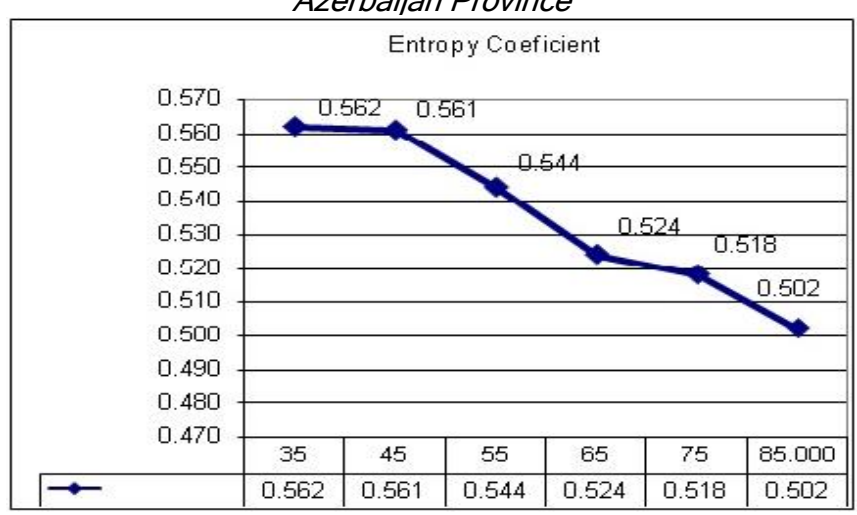

In this equation, if $R=0$, it expresses the absolute concentration of population in a region and if $R=1$, it expresses that the dispersion is strong and population is distributed uniformly and relatively. With this model, we are able to obtain the anarchy ratio in the urban hierarchy of East Azerbaijan by analyzing the statistics of regional cities. On this basis, planners and managers will be able to establish a stable urban system by computing inconsistency ratio (Table 2; Fig. 1).

Table 3. Determination of cities hierarchy in 1957 using class difference method

\begin{tabular}{|c|c|c|c|c|}
\hline Raw & $\begin{array}{c}\text { percen } \\
\mathrm{t}\end{array}$ & $\begin{array}{c}\text { Number of } \\
\text { cities }\end{array}$ & Population group & City \\
\hline 1 & 5.3 & 1 & $289996-232116$ & Tabriz \\
\hline 2 & - & - & $232116-174236$ & - \\
\hline 3 & - & - & $174236-116356$ & - \\
\hline 4 & - & - & $116356-58476$ & - \\
\hline 5 & 94.7 & 18 & $58476-596$ & Other cities \\
\hline Sum & 100 & 19 & & - \\
\hline
\end{tabular}

Urban hierarchy determination using class difference method

This scientific method can be implemented using statistic formulas especially by maximum and minimum number of population (Hekmatnia \& Mousavi, 2007). General structure of this model is as follows:

First step: Determination of variation of population in cities

$\mathrm{R}=\operatorname{Max}(\mathrm{p})-\operatorname{Min}(\mathrm{p})$

Second step: Determination of number of classes using Storages formula

$\mathrm{K}=1+3 / 3 \log \mathrm{N}$

Third step: Determination of amount of class difference $\mathrm{H}=\mathrm{R} / \mathrm{K}$

Fourth step: Establishment of matrix and classification of cities

Hierarchy in East Azerbaijan province was evaluated based on 6 statistical periods (1957, 1967, 1977, 1987, 1997 and 2007), using population factor.

There are serious differences in the urban classes of the province, in all studied periods. These differences increased over time. In 1957, differences of classes of urban levels were 3 and they were 4 from 1967-1997. In 2007, these differences reached its maximum - 5 classes 
Table 4. Determination of cities hierarchy in 1967 using class difference method

\begin{tabular}{|c|c|c|c|c|}
\hline Raw & Percent & $\begin{array}{c}\text { Number } \\
\text { Of Cities }\end{array}$ & Population Group & City \\
\hline 1 & 3.3 & 1 & $403413-336396$ & Tabriz \\
\hline 2 & - & - & $2336396-69379$ & - \\
\hline 3 & - & - & $269379-202362$ & - \\
\hline 4 & - & - & $202362-135345$ & - \\
\hline 5 & & - & $135345-68328$ & - \\
\hline 6 & 7.96 & 29 & $68327-1309$ & $\begin{array}{c}\text { Other } \\
\text { cities }\end{array}$ \\
\hline Sum & 100 & 30 & & - \\
\hline
\end{tabular}

Table 5. Determination of cities hierarchy in 1977 using class difference method

\begin{tabular}{|c|c|c|c|c|}
\hline Raw & Percent & $\begin{array}{c}\text { Number } \\
\text { Of Cities }\end{array}$ & Population group & City \\
\hline 1 & 3.3 & 1 & $597976-498652$ & Tabriz \\
\hline 2 & - & - & $498652-399328$ & - \\
\hline 3 & - & - & $399328-3000004$ & - \\
\hline 4 & - & - & $3000004-200680$ & - \\
\hline 5 & - & - & $200680-101356$ & - \\
\hline 6 & 7.96 & 29 & $101356-2031$ & $\begin{array}{c}\text { Other } \\
\text { cities }\end{array}$ \\
\hline Sum & 100 & 30 & & - \\
\hline
\end{tabular}

Table 6. Determination of cities hierarchy in 1987 using class difference method

\begin{tabular}{|c|c|c|c|c|}
\hline Raw & Percent & $\begin{array}{c}\text { Number } \\
\text { of cities }\end{array}$ & Population group & City \\
\hline 1 & 3.3 & 1 & $971482-809946$ & Tabriz \\
\hline 2 & - & - & $809946-648410$ & - \\
\hline 3 & - & - & $648410-486874$ & - \\
\hline 4 & - & - & $486874-325338$ & - \\
\hline 5 & - & - & $325338-163802$ & - \\
\hline 6 & 7.96 & 29 & $163802-2266$ & $\begin{array}{c}\text { Other } \\
\text { cities }\end{array}$ \\
\hline Sum & 100 & 30 & & - \\
\hline
\end{tabular}

Table 7. Determination of cities hierarchy in 1997 using class difference method

\begin{tabular}{|c|c|c|c|c|}
\hline Raw & Percent & $\begin{array}{c}\text { Number } \\
\text { of cities }\end{array}$ & Population group & City \\
\hline 1 & 6.2 & 1 & $1191043-992959$ & Tabriz \\
\hline 2 & - & - & $992959-794875$ & - \\
\hline 3 & - & - & $794875-596791$ & - \\
\hline 4 & - & - & $596791-398707$ & - \\
\hline 5 & - & - & $398707-200623$ & - \\
\hline 6 & 4.97 & 3839 & $200623-2539$ & $\begin{array}{c}\text { Other } \\
\text { cities }\end{array}$ \\
\hline sum & 100 & & & - \\
\hline
\end{tabular}

(Table 3-8). It is worthy to note that the references of these tables are Web-sites of Iran's Statistical Offices and authors' own calculations.
Table 8. Determination of cities hierarchy in 2007 using class difference method

\begin{tabular}{|c|c|c|c|c|}
\hline Raw & Percent & $\begin{array}{c}\text { Number } \\
\text { of cities }\end{array}$ & Population group & City \\
\hline 1 & $1 / 8$ & 1 & $1398060-1198627$ & Tabriz \\
\hline 2 & - & - & $1198627-999194$ & - \\
\hline 3 & - & - & $999194-799761$ & - \\
\hline 4 & - & - & $799761-600328$ & - \\
\hline 5 & - & - & $600328-400895$ & - \\
\hline 6 & - & - & $400895-201462$ & Other cities \\
\hline 7 & $98 / 2$ & 56 & $20146-2029$ & - \\
\hline sum & 100 & 57 & & \\
\hline
\end{tabular}

\section{Conclusion}

East Azerbaijan province had 19 cities in the year of 1957 whose $61.5 \%$ of urban population was resident in

Tabriz City. This year, the degree of entropy of province cities was 0.562 , which is the average development of the relative balance in urban system. In this year, the cities of Maragheh, Ahar and Mianeh were the most important and populated cities of the province. In 1967, entropy value considerably decreased to 0.561 . In 2011, the number of province cities increased to 30 from 19 and the portion of Tabriz population decreased to $58.1 \%$ in 1967 from $61.5 \%$ in 1957 . Due to the decrease of Tabriz's portion in the urban system of province and the increment of low-populated cities, entropy degree of the province has faced a decrease. In 1977, Tabriz portion increased to $60.3 \%$ from $58.1 \%$ in 1967 and due to the increment of province cities to 30 , entropy degree of the province decreased to 0.554 . This year, other large cities of province like Maragheh, Mianeh and Marand have faced a decrement in the portions of province population. In other words, in spite of increment in the urban population of the province in these years, the main part of this population inhabit in Tabriz City and this city has increased its portion in province population compared with 1967.

In 1977, the capitation results showed a significant increment of the centralization of Tabriz in the urban system of East Azerbaijan. This year, the portion of Tabriz population had an increment, similar to the past decades, while the population in the other large cities decreased. Entropy degree of this year has decreased to 0.524 in 1987 from 0.544 in 1977 showing the increment of anarchy in the urban system of the province. Continuing the situation of the past decades', entropy degree decreased to 0.518 in 1996 . However, population portion of Tabriz city has decreased to $59.4 \%$ in 1997 from $61.2 \%$ in 1987 . Also, other large cities of province have encountered some changes. In 2007, the decrement of population portion of Tabriz continued and population portion of Tabriz city reached to $58.19 \%$. Population portion of other large cities encountered some decrements as well. It is important to note that the number of province cities increased to 57 in 2007 from 39 in 1997. So, the population portion of Tabriz had 
encountered more decrement, compared with the population of province, the entropy degree decreased to 0.502. Results of class difference method indicated illogical and uncoordinated urban classification of the province, as well. This problem led to severe rupture in the urban network of the province. In all 6 statistical periods, more than $94 \%$ of the province cities were located in the lower classes and only Tabriz city was in the highest level with a great difference in all periods compared with the other cities. Also, it can be pointed that there is no city which is classified as a medium city in the province classification, while there are many small and insignificant cities in the urban network of the province.

\section{References}

1. Azimi N (2002) Urbanization quest and fundamental of urban system. Nika Publication. pp: 36.

2. Azizpour M (1997) Assessment of ability of natural environment and physical expansion of city. Tarbiat Modarres University, Geography Faculty.

3. Batiste J and Dezer B (1999) City, translated by Ali Esrafi. Art Univ.

4. Behforouz F (1999) Philosophy of methodology of scientific research in geography. Univ., Tehran.

5. Chadwick A (1987) Models of urban \& regional system in developing countries. NY.

6. Dolphus E (1995) Geographic analysis, translated by Sirous Sahami.

7. Ebrahimzadeh E and Negahban Marvi M (2006) Analysis of urbanization and ranking new cities in Iran. Geographic Res. Magaz. pp: 75, 154.

8. Eftekhari A and KHarameh H (1997) Location of rural settlements' hierarchy. Geographic Res. Magaz., Mashhad. pp: 35.

9. Fanni Z (2003) Small cities, another approach to regional development, Tehran. Organization of Country's Municipalities.

10. Gilbert A (1989) Development planning and spatial structure. John Wiley. pp: 338.

11. Haget $P(1997)$ New combined geography. $2^{\text {nd }}$ ed., Translated by Shapour Goudarzinejhad, Samt.

12. Harvey D (2001) Social equanimity and city, Translated by Farrokh Hesamian and Mohammad Reza Hayeri and Behrouz Monadizadeh. City's Processing \& Planning Company.

13. Hataminejhad H (2005) Rank of Gaen city in Khorasan city network. Human \& Soc. Sci., University of Shahid Chamran, Ahvaz. Vol. 1.

14. Hekmatnia $\mathrm{H}$ and Mousavi M (2007) Application of model in geography emphasizing urban and regional planning. Elm Novin press, 1st Ed, Yazd. pp: 188190.

15. Hogget P (2001) Geography, Global synthesis. Prentice Hall.

16. Linch K (1998) Theory of form of fine cities. Translated by Seyyed Hossein Bahreini.
17. Malek Hosseini A (2000) Analysis of spatial organization of Markazi Province, using entropy model. Amayesh. pp: 1.

18. Misra RP (1975) Recognition of methods to local planning for rural civilizing in Iran. Center of Res. \& Training in Regional Planning.

19. Nazarian A (1994) Urban network and hierarchy system of Iran's cities. Quarterly of Literature Faculty. Univ. Tarbiat Moallem.

20. Nazarian A (1996) Urban geography in Iran. Publ. Payam Noor University.

21. Organization of management and planning (2000) Documents of third socio-economic and cultural development plan.

22. Papoli Yazdi M (1994) Centralization and decentralization and their effects, article collection of new cities, new culture in urbanization. Tehran, New Cities Civilization Company. pp: 305.

23. Rafieian M (1997) Spatial organization in Iran, emphasizing urban systems. Ph.D. Thesis in Urban Geog., Tarbiat Modarres University.

24. Rezvani M (1996) A survey on the organization of spatial-location settlements and its optimization in rural areas of Shahrood. Quarterly of Geog. Res. pp: 388.

25. Shakoui H (1996) New Perspectives in urban geography. $4^{\text {th }}$ ed., Samt Press.

26. Shebling J (1999) What is the geography? Translated by Siroos Sahami. Mohaghegh Press .

27. Statistical office of Iran, population of Iran cities (1967, 1977, 1987, 1997 and 2007).

28. Statistical office of Iran, public census of population and houses, 1967, 1977, 1987, 1997 and 2007.

29. Website of Iran statistical office (2006). www.sci.org.ir

30. Wheeler James $O$ and Muller Peter O (1986) Economic geography. John Wiley \& Sons, Inc, Canada. pp: 384.

31. Ziari K (2004) Doctrines, theories and models in regional planning, 1st ed., University of Yazd. 